\title{
IDÉIAS
}

\section{Centro-Sul Garante o Próximo Presidente}

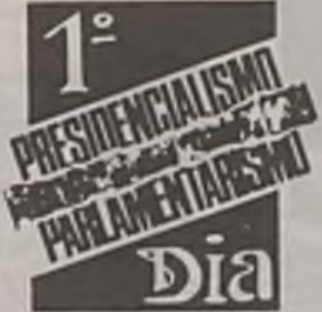

A reflexão que hoje fazemos sobre o parlamentarismo e o presidencialismo se insere, evidentemente, no contexto político em que atualmente nos encontramos, e diz respeito às grandes direções que pretendemos imprimir ao nosso pais nesse momento de definição dos rumos constitucionais.

O direito público, em geral, e o direito constitucional, em particular, trata de um conjunto de regras que repassam incompetência e permitem o exercício do poder.

A clássica função entre o parlamentarismo e o presidencialismo diz respeito, para lembrar uma famosa frase de Rui Barbosa, na sua plataforma de 1910, à busca da estabilidade e o esforço de coibir a irresponsabilidade. E, nesse sentido, as formas de parlamentarismo sempre buscam entre o Executivo e o Legislativo uma interdependência por integração, a que fez referência o Prof. Miguel Reale Junior na sua exposição.

No presidencialismo sempre se procura a idéia de uma independência recíproca entre o Legislativo e o Executivo, e um esforço muito grande do Supremo Tribunal buscando assegurar esta independência recíproca.

Nós tivemos, nas duas esplêndidas exposições de hoje, uma análise de como o modelo francês e o modelo espanhol procuraram lidar com esses problemas. No caso do modelo francês, a idéia da grande arbitragem final cabendo ao sufrágio universal, e, no modelo

Celso Lafer é Professor de Ciência Política da Universidade de São Paulo. Debatedor do 1: Dia.
Prof. Celso Lafer

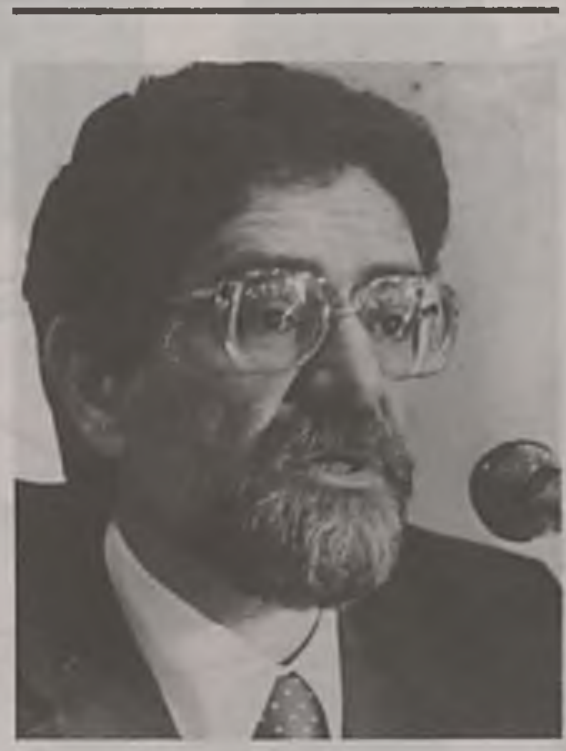

espanhol, esta predominância atribuida ao chefe de governo na sua relação com o poder Legislativo.

Eu vou procurar cingir a minha observação a un problema que me parece fundamental, e que é normal em toda reflexão sobre parlamentarismo e presidencialismo, a um sistema eleitoral e ao regime de partidos. Não vou entrar no regime de partidos, mas quero realçar um pouco as conseqüências políticas das leis eleitorais.

Existe uma geografia eleitoral, e esta é muito importante sobretudo num país como o nosso, que tem não só a experiência e o peso da federação sobre um problema fundamental, como também a necessidade de lidar com uma variedade e com uma disparidade regional muito significativa.

Lembro que esse tema da geografia eleitoral é um tema fundamental. Penso que, por exemplo, no caso dos Estados Unidos, sem dúvida o deslocamento do eleitorado e do poder econômico do leste dos Estados Unidos para o Texas e para a Califórnia explicam certas mudanças muito importantes. $E^{\prime}$ indis- cutivel que o Presidente Reagam resultou de uma nova maioria e que essa nova maioria está vinculada ao deslocamento do poder eleitoral e do poder econômico do Leste dos Estados Unidos, que tradicionalmente exerceu esta hegemonia no sistema norte-americano para o Texas e para a Califórnia.

Penso chamar a atenção sobre este aspecto porque, se há um aspecto, ou se há uma dimensão que foi consagrada pelo processo de iransição política no Brasil, é a idéia da eleição direta do Presidente da República por dois turnos por meio de uma maioria absolu1a. Isso significa, em poucas palavras, que só poderá ser eleito Presidente da República quem tiver sucesso e conseguir a maioria dos votos do centro-sul do Brasil, que são os volos majoritários do nosso atual sistema político brasileirn. Isto é um dado que me parece fundamental porque a ele se vincula o relacionamento do Presidente da República com o Legislativo nas formas mais puras de presidencialismo ou nas eventuais formas de parlamentarização do poder que vierem a ser consagradas pela futura Constituição.

Há, como sempre, e lodos nós o sabemos, um papel importante atribuido ao Senado, como o equilibrio da Federação, é clássico e vem sendo exercido na nossa função republicana.

$\mathrm{Na}$ discussão do impacto das leis eleitorais na composição da Câmara, sempre se discute a relação entre uma sub-representação do Centro-Sul e uma sub-representação dos demais estados da Federação.

Este foi nó sistema da Constituição mais rica nesse ponto de vista porque é o que deu margem à extensão do voto e à das franquias que caracterizam a republica populista de 45 a 64. Os dados mostram que a equação eleitoral foi extremamente bem elaborada, permitinda, no jogo do processo de aprovação das leis, graças ao sistema eleitoral, uma representação extremamente equilibrada, que impe- 


\section{IDÉIAS}

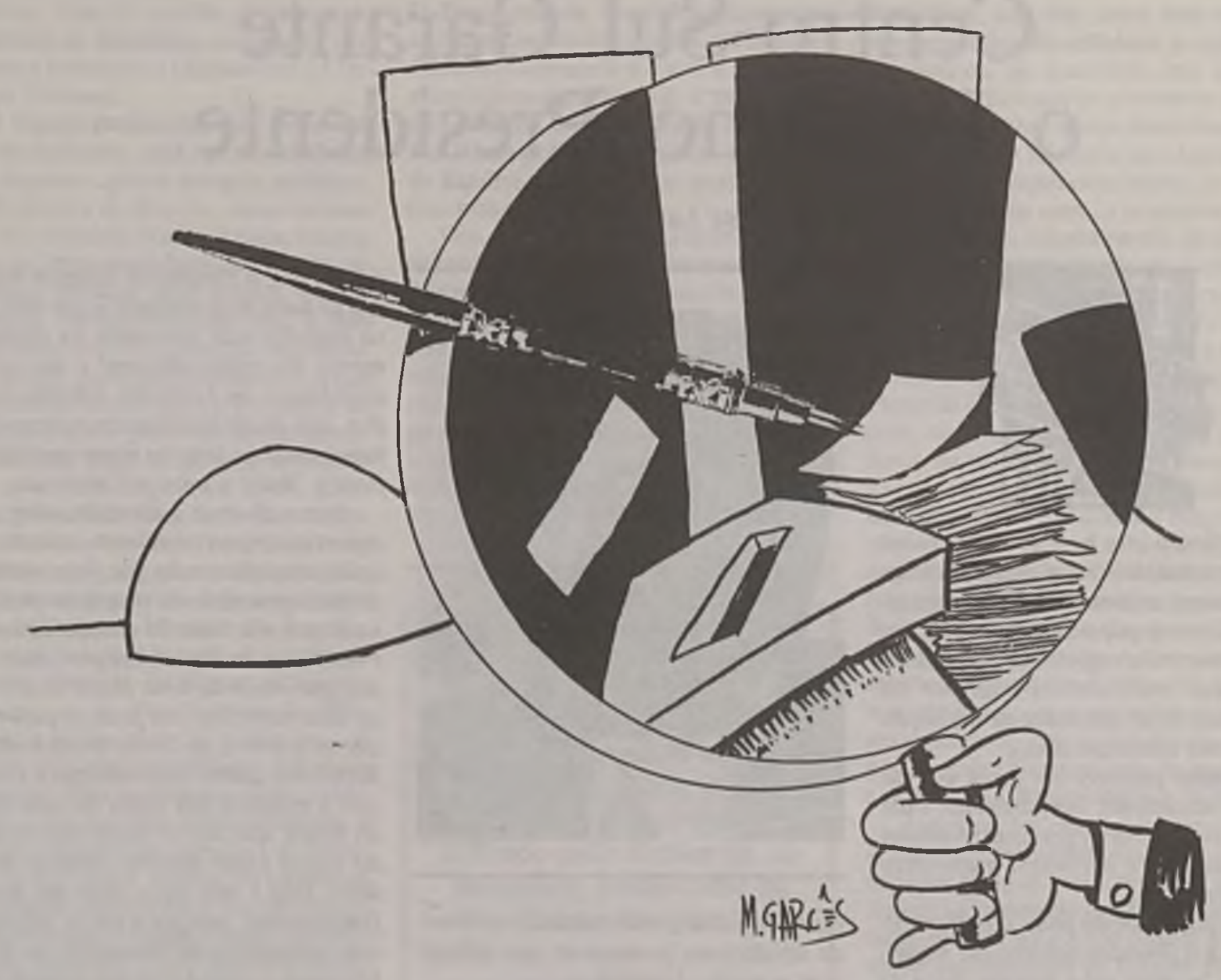

dia, vamos dizer assim, a hegemonia do Centro-Sul no processo de deliberação parlamentar, e isso tinha um papel muito importante na composição do equilíbrio do Pais, da União e da Féderaçãa

Esse dado é um dado importante porque nesse relacionamento entre o Executivo e o Legislativa nesse periodo livre que vivemos, de 45 a 64, irouxe, de um lada crises, mas trouxe, de outro lada um certo tipo de proposta, um certo tipo de equilibria

Penso nesses aspectos porque, se viermos a atribuir ao vota, ao sufnágio, esta função de arbitragem-chave que ele tem na França, como foi exposto pelo Prof. Baradi, e se nós tivermos pensando no governo exercendo certas funções de governo como a tributação e a de orçamento $e$ a de direção política, o relacionamento entre as caracteristicas da Câmara e o Executivo passa por uma reflexão, pelo sistema eleitoral. Se o sistema se mantiver como sendo o da representação proporcional, se vier a ser um sistema mista se con- tinuar a persistir em super-representações de região, isso terá um efeito decisivo sobre a governabilidade ou a não governabïlidade do governo, sobre a gestão da crise e sobre o encaminhamento destas situações.
Não podemos ficar no presidencialismo puro com o presidente só, isolado, com esse divórcio que se sente presente na vida brasileira republicana. É um presidencialismo imperial, que acaba por sempre levar ao confronto, mesmo quando há Constituinte.
Eu faço esta reflexão lembrando de uma distinção que faz um famoso juiz inglês, que dizia que havia uma diferença entre professores e advogados. Que os advogados procuram encontrar uma soluçāo para todos os problemas, e os professores procuram encontrar um problema em qualquer solução.

Como eu estou aqui na função de professor, eu estou procurando apontar os problemas que existem em tais ou quais soluçōes, e queria realçar a absoluta importância da análise das conseqüências das leis eleitorais no processo de definição da forma de governo no Brasil e na análise de qualquer processo de parlamentarização do poder que vier a ser adotado na Nova Constituição." 